\title{
Original
}

[Journal of Environmental Chemistry Vol.12, No.2, pp.353-360, 2002]

\section{TLC-Fractionation and GC/MS Characterization of Mutagenic Substances in Chlorinated 4-Alkylphenol Solutions}

\author{
Sukeo ONODERA ${ }^{1)}$, Masashi SAKOTA ${ }^{1)}$, \\ Minoru KUWAHARA ${ }^{2)}$ and Yasuaki MORI ${ }^{3)}$ \\ ${ }^{1)}$ Faculty of Pharmaceutical Sciences, Tokyo University of Science \\ (12 Ichigaya-funagawara-machi, Shinjuku-ku, Tokyo 162-0826) \\ ${ }^{2)}$ Department of Chemistry, The Polytechnic University \\ (Hashimoto, Sagamihara, Kanagawa 229-1196) \\ ${ }^{3)}$ Kanagawa Prefectural Public Health Laboratory \\ (1-1-1 Nakao, Asahi-ku, Yokohama, Kanagawa 241-0815)
}

[Received March 11, 2002]

\begin{abstract}
Summary
The diethyl ether extracts from aqueous 4-alkylphenol solutions after treatment with chlorine were mutagenic to the Ames Salmonella tester strains TA98 and TA100 in the absence of rat liver homogenate. Gas chromatography/mass spectrometry (GC/MS) showed the occurrence of chlorinated products in the extracts; chloro-4-alkylphenols, chloro-4alkylquinones and chlorinated 4 -alkylphenol dimers. The diethyl ether extracts were fractionated into several fractions by polyamide thin-layer chromatography (TLC). The fractionated components were examined for mutagenicity by means of Ames assay, and were identified by GC/MS. TLC fractionation of the extracts revealed that two components present in the extracts are mutagenic. GC/MS analyses indicated the presence of 2,6-dichloro-4hydroxy-4-alkylcyclohexa-2,5-dien-1-ones as the major mutagen and chlorinated 4-alkylphenol dimers as minor mutagenic compounds in the chlorinated 4 -alkylphenol solutions.
\end{abstract}

Key words: water chlorination, 4 -alkylphenol, mutagenicity, chloroalkylsemiquinone

\section{INTRODUCTION}

Mutagenic and carcinogenic organic compounds found in source water ${ }^{1)}$ and drinking water ${ }^{2)}$ have recently caused concern as to their potential effects on human health. Mutagenicity in source waters has generally been attributed to contamination by industrial waste or agricultural run-off, and to a lesser extent to naturally occurring substances. In comparison studies of raw water vs. finished water, Glatz et al. ${ }^{3)}$ and Maruoka and Yamanaka ${ }^{4)}$ suggested that chlorination may play a major role in the production of organic muta- gens in potable water. Subsequent laboratory studies by Cheh et al. ${ }^{5)}$ in which a drinking water treatment process was simulated, clearly demonstrated that nonvolatile mutagens were produced by chlorine disinfection. Several volatile compounds such as chloroacetones and chloropropenal, and chlorinated hydroxyfuranone (MX), exhibiting mutagenicity have been identified to be present in chlorinated water, ${ }^{6,7}$, but many of the nonvolatile mutagenic substances have not been fully characterized.

One class of compounds recognized as important pollutants in aquatic environment is phenols because of 
off-favor in water and their high toxicity. Therefore, it seems that mutagens are formed as a result of the reaction of chlorine with phenolic compounds that may be present in the water sources. Direct support for this hypothesis has been provided by Rapson et al. ${ }^{8)}$ and by our recent studies which demonstrated that phenols react with chlorine to form direct-acting mutagenic products $^{9-13)}$. We now present more detailed finding on the characterization of the mutagens formed by the reactions of chlorine with 4-alkylphenols in aqueous solution. 4-Alkylphenols were chosen in this work because these compounds have been used as intermediates in the production of important industrial chemicals and also identified as being present in aquatic samples ${ }^{12)}$.

\section{EXPERIMENTAL}

\section{Chemicals}

4-Alkylphenols $\left(\mathrm{C}_{1}\right.$ - $\left.\mathrm{C}_{9}\right)$, 2-chloro-4-alkylphenols, 2,6dichloro-4-alkylphenols, Irgasan DP 300 (as a typical chlorinated phenoxyphenol) and trichloroacetic acid used for product identification and mutagenicity tests were commercially products. Standard solutions of these compounds both alone and as mixtures were prepared by dissolving the compounds in methanol and subsequent dilution. Chlorinated aqueous solution was prepared by diluting sodium hypochlorite solution (ca. $10 \%$ available Cl) (Nacarai Tesque, Kyoto Japan) with $0.1 \mathrm{M}$ potassium dihydrogen phosphate/sodium tetraborate decahydrate solution. The hypochlorite concentrations were determined by iodometric titration. Polyamide $11 \mathrm{~F}_{254}(20 \times$ $20 \mathrm{~cm}$, thickness $0.15 \mathrm{~mm}$ ) precoated thin-layer chromatographic (TLC) plates (Merck, Darmstad, Germany) were used to fractionate the diethyl ether extracts.

\section{Aqueous chlorination of 4-alkylphenol and extrac- tion of reaction mixture}

Individual aqueous 4-alkylphenol solutions $(0.5$ $\mathrm{mmol} / \mathrm{\ell}$ ) were treated with 5 equiv. of chlorine (as $\mathrm{HOCl}$ ) at $20{ }^{\circ} \mathrm{C}$ for $1 \mathrm{~h}$ at $\mathrm{pH} 5$. The unreacted chlorine was removed by addition of sodium thiosulfite solution. The reaction mixture was then acidified to $\mathrm{pH} 2$ with $6 \mathrm{M}$ hydrochloric acid before extraction with two $200-\mathrm{m} \ell$ portions of diethyl ether. The extracts were dried over anhydrous sodium sulfate and concentrated under vacuum at $40{ }^{\circ} \mathrm{C}$ to volumes suitable for polyamide TLC, GC and GC/MS analyses. Part of the diethyl ether extract was resuspended in $1 \mathrm{~m} \ell$ of dimethyl sulfoxide (DMSO) for mutagencity assays.

\section{Fractionation of mutagenic extracts by TLC}

Individual diethyl ether extracts (about $50 \mathrm{mg}$ ) were fractionated into several fractions by TLC on polyamide plates using chloroform as a developing solvent. The detection of spots on the plates was performed by UV irradiation. The plates were also sprayed with $0.5 \%$ bromocresol green solution in order to detect acidic products. The separated zones were scraped off by using special recovery tubes (Wako, Osaka, Japan) and the adsorbed substances were eluted with diethyl ether. The recoveries (\%, $\mathrm{w} / \mathrm{w})$ of individual fractions were calculated as [(amount of sample recovered)/amount of sample applied) $] \times 100$.

\section{Product resolution and characterization}

A Hitachi Model 263-30 gas chromatograph equipped with a flame ionization detector and a $2 \mathrm{~m} \times$ $3 \mathrm{~mm}$ i.d. glass column packed with $2 \% \mathrm{OV}-1$ on Uniport HP (60-80 mesh) was programmed from 100 to $260{ }^{\circ} \mathrm{C}$. The injector and detector temperatures were $260{ }^{\circ} \mathrm{C}$. The helium gas flow-rate was $30 \mathrm{~m} \ell / \mathrm{min}$. A Hitachi D-2500 chromato-integrator was used to determine the retention times and peak areas on the chromatograms.

A Hitachi $\mathrm{M}-80$ combined mass spectrometer-gas chromatograph with a Hitachi M-003 data processing system was used for the qualitative analyses of samples under the following conditions: ion source temperature, $250{ }^{\circ} \mathrm{C}$; trap current, $70 \mu \mathrm{A}$; and electron energy, $70 \mathrm{eV}$. The column and chromatographic conditions were the same as described above.

\section{Mutaginicity tests}

The mutagenicity of the samples was tested according to the method of Ames et al. ${ }^{15)}$ with minor modifications. Liver homogenates (S9) was prepared from male Sprague-Dawley rats, which had been pretreated with phenobalbital and 5,6-benzoflabone to activate enzymes. Addition of the $\mathrm{S} 9 \mathrm{mix}$ was conducted to confirm whether test compounds were indirect-acting mutagens which required mammalian metabolic activation. Salmonella typhimurium strains TA98 and TA100 were used throughout the experiments. The samples were dissolved in DMSO and preincubated with a tester strain at $37{ }^{\circ} \mathrm{C}$ for $20 \mathrm{~min}$ (prior plating) with and without $\mathrm{S} 9 \mathrm{mix}$. A buffer was used when $\mathrm{S} 9$ mix was not employed. After addition of the test sam- 
ples, the plates were incubated at $37{ }^{\circ} \mathrm{C}$ for 2 days. The assay was performed in triplicate for each sample. The mutagenic activity is expressed as the mean value of revertants.

\section{RESULTS AND DISCUSSION}

\section{Mutagenic potential formation of 4-alkylphenols during aqueous disinfection with chlorine}

Treatment with chlorine of 4-alkylphenols in aque- ous solutions and subsequent mutagenicity assays of these diethyl ether extracts were performed to evaluate the mutagenic potential formation of these compounds. Table 1 is a summary showing the experimental conditions for aqueous chlorination of 4-alkylphenols and the results of Ames tests for the diethyl ether extracts. Figure 1 shows typical examples of the actual mutagenic responses of extracts from chlorine-treated 4alkylphenol solutions on Salmonella typhimurium TA100.

Table 1 Mutagenic potential formation (MPF) of 4 -alkylphenol solutions by chlorination

\begin{tabular}{|c|c|c|c|c|c|c|c|c|c|}
\hline \multirow{3}{*}{$\begin{array}{l}\text { Expt. } \\
\text { No. }\end{array}$} & \multicolumn{2}{|c|}{ Compound examined } & \multirow{3}{*}{$\begin{array}{l}\mathrm{HOCl} \\
\text { Conc. } \\
(\mathrm{mM})\end{array}$} & \multirow{3}{*}{$\begin{array}{c}\text { Solution } \\
\mathrm{pH}\end{array}$} & \multirow{3}{*}{$\begin{array}{l}\text { Reaction } \\
\text { Time } \\
\text { (h) }\end{array}$} & \multirow{2}{*}{\multicolumn{4}{|c|}{$\begin{array}{l}\text { MPF in TA98 MPF in TA100 } \\
\text { net revertants } / \mathrm{nmol} \text { as the parent compd. }\end{array}$}} \\
\hline & \multirow{2}{*}{ Name } & \multirow{2}{*}{$\begin{array}{l}\text { Conc. } \\
(\mathrm{mM})\end{array}$} & & & & & & & \\
\hline & & & & & & $-\mathrm{S} 9$ & $+\mathrm{S} 9$ & $-S 9$ & $+\mathrm{S} 9$ \\
\hline 1 & 4-Methylphenol & 0.5 & 2.5 & 5 & 1 & 1.23 & 0.32 & 23.78 & 3.20 \\
\hline 2 & 4-Ethylphenol & 0.5 & 2.5 & 5 & 1 & 0.82 & 0.21 & 15.80 & 2.12 \\
\hline 3 & 4-Propylphenol & 0.5 & 2.5 & 5 & 1 & 0.79 & 0.20 & 12.78 & 1.65 \\
\hline 4 & 4-Butylphenol & 0.5 & 2.5 & 5 & 1 & 0.91 & 0.23 & 11.25 & 1.46 \\
\hline 5 & 4-Pentylphenol & 0.5 & 2.5 & 5 & 1 & 0.67 & 0.17 & 10.87 & 1.41 \\
\hline 6 & 4-Hexylphenol & 0.5 & 2.5 & 5 & 1 & 0.55 & 0.14 & 9.95 & 1.29 \\
\hline 7 & 4-Heptylphenol & 0.5 & 2.5 & 5 & 1 & 0.30 & 0.08 & 7.50 & 0.97 \\
\hline 8 & 4-Octylphenol & 0.5 & 2.5 & 5 & 1 & 0.20 & 0.05 & 4.00 & 0.52 \\
\hline 9 & 4-Nonylphenol & 0.5 & 2.5 & 5 & 1 & 0.10 & 0.03 & 2.50 & 0.32 \\
\hline Positi & ve control & 2-Nitr & luorene & & & 31.43 & - & - & - \\
\hline & & Sodiu & Azide & & & - & - & 33.00 & - \\
\hline & & Benzo & (a) pyren & & & - & 28.00 & - & 37.00 \\
\hline
\end{tabular}

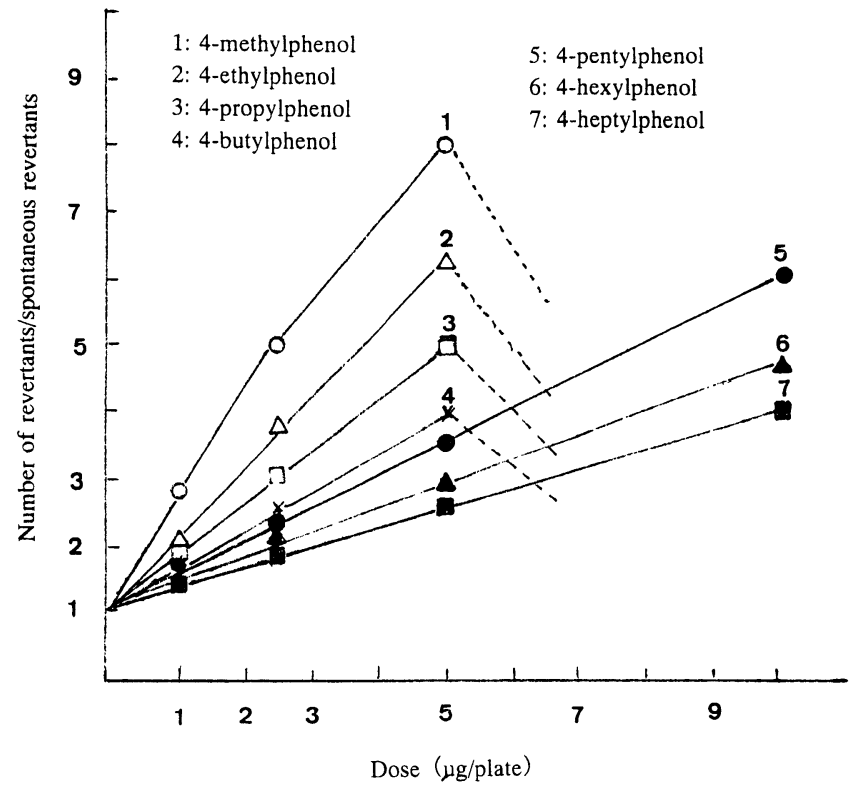

Fig. 1 Mutagenicity of diethyl ether extracts of aqueous 4-alkylphenol solutions after treatment with hypochlorous acid (5 equivalents of $\mathrm{HOCl}$ per mole of compound) at $\mathrm{pH} 5$ for $1 \mathrm{~h}$, as measured with S. Tiphimurium TA100 in the absence of S9 mix 
None of the 4-alkylphenols before aqueous chlorination were mutagenic in the TA98 and TA100 strains with or without S9 mix. Aqueous chlorination, however, generated mutagens from non-mutagenic parent compounds. Greater mutagenic potential formation on the TA100 strain without S9 mix were observed for the 4-alkylphenol-hypochlorite reactions, as compared with those detected on the TA98 strain (Table 1). An increase in the alkyl chain length in the phenol ring decreased the mutagenic potential formation when 4alkylphenols were treated with chlorine in an acidic aqueous solution of $\mathrm{pH} 5$ for $1 \mathrm{~h}$. A weak mutagenic potential formation on the both tester strains without S9 mix was observed even for the nonylphenol-chlorine reaction.

A previous study ${ }^{13)}$ revealed that treatment with a high chlorine dose (20 equiv. of $\mathrm{HOCl}$ per mole of compound) of 4-methylphenol in neutral aqueous solution ( $\mathrm{pH}$ 7) produces a series of highly chlorinated compounds. These were chlorinated 4-methylphenols, chlorohydroxylated 4-methylquinones and polychlorinated 4methylphenol dimers. Among these chlorinated com- pounds, polychlorinated 4-methylphenol dimers have also been shown to be mutagenic towards test strain TA100 without S9 mix. However, our recent studies ${ }^{9,11)}$ demonstrated that aqueous chlorination of 4-methylphenol produces the mutagen (2,6-dichlorotolquinol) even at a low chlorine dose (5 equiv. of $\mathrm{HOCl}$ per mole of compound) in an acidic solution of $\mathrm{pH} 5$. Since mutagenic substances occurring in the other 4alkylphenol-hypochlorite reactions were not yet isolated and characterized, further GC/MS studies combined with TLC fractionation of the mutagenic diethyl ether extracts were performed again in this work.

\section{TLC fractionation of mutagenic diethyl ether ex- tracts}

A preliminary fractionation of the mutagenic diethyl ether extracts from the chlorine-treated 4-methyl-, ethyl-, propyl- and butylphenol solutions was performed by TLC using polyamide plates. The TLC results for the original extracts and mutagenicity tests with strain TA100 in the absence of S9 mix are presented in Figs. 2 and 3. When the original diethyl

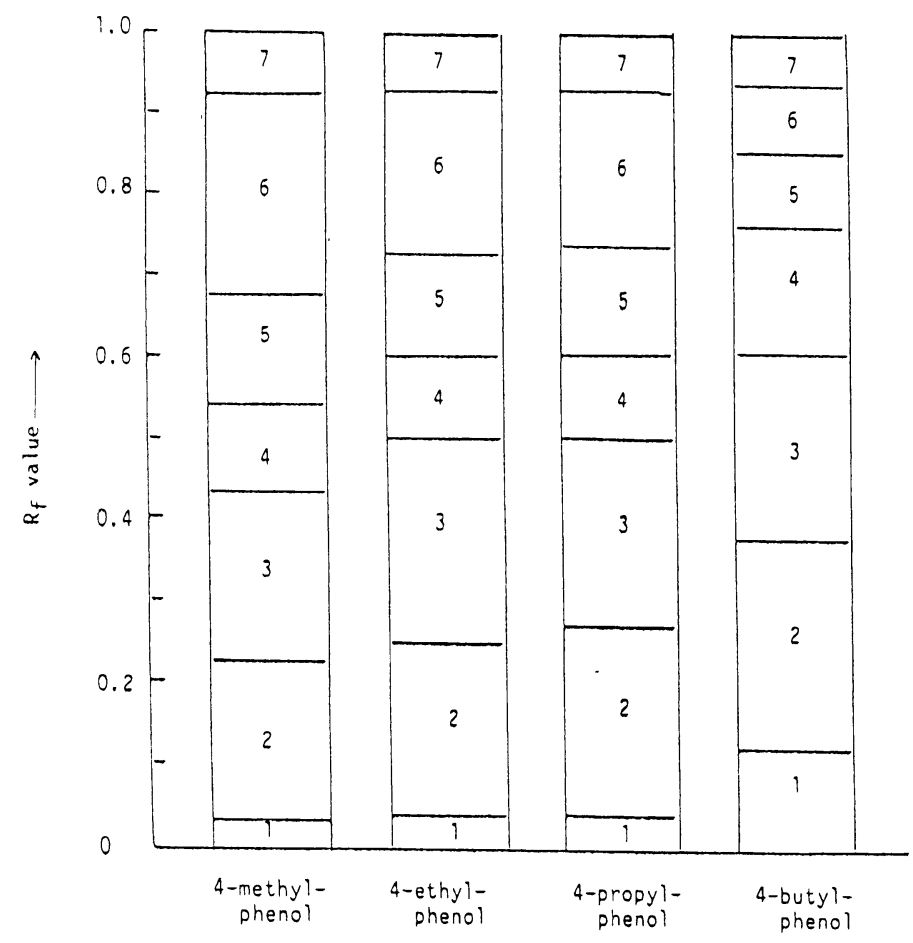

Fig. 2 Fractionation of mutagenic diethyl ether extracts of chlorine-treated 4-alkylphenol solutions by polyamide TLC

For TLC conditions, see Experimental 
ether extracts were fractionated on polyamide plates, the recovery in the fractions was approximately $60 \sim 75$ $\%$ (w/w) of the amount of samples applied, while the mutagenicity recovered from the plates was about $50-60 \%$ of the over all activity applied. These results indicate that mutagenic substances in the extracts are converted into non-mutagenic materials during the TLC fractionations ${ }^{14)}$. In addition, most of the mutagenic materials were found to be concentrated in each fraction 3 on the polyamide plates (Figs. 2 and 3 ). This suggests that the mutagenic materials in the extracts have intermediate polarity.

The dose-response curves of the typical TLC-fractionated samples are shown in Fig. 3. Among these components, each fraction 3 showed the strongest mutagenic response, and their mutagenic potentials were approximately 10-24 revertants/nmol, dependent on the alkyl chain length in the phenol ring. These potentials were nearly the same as those reported for 1,1,3-trichloroacetone, 2-chloropropenal and sodium azide as be- ing used for positive reagent in Ames assay, but much lower than that found for chlorinated hydroxyfuranone (MX), which have been cited as important mutagens in kraft chlorination effluents ${ }^{6}$. Fractions 6 and 7 also exhibited mutagenicity, but the activity was very low as compared with those of each fraction 3. Most of the mutagencity of original extacts obtained from the chlorinated 4-alkylphenol solutions were thus accounted for by each fraction 3 .

\section{GC and GC/MS studies of the TLC fractions}

In order to obtain further information on the mutagenic components present in the diethyl ether extracts of chlorine-treated 4-alkylphenol solutions, the components (fractions 1-7) obtained by polyamide TLC were investigated by means of $\mathrm{GC}$ and GC/MS. Fig. 4 shows the gas chromatograms (flame ionization detection) of the original extracts and fractions 3,4 and 7. 2Chloro-4-alkylphenols and 2,6-dichloro-4-alkylphenols, corresponding peaks 1 and 2 , in Fig. 4 were distrib-

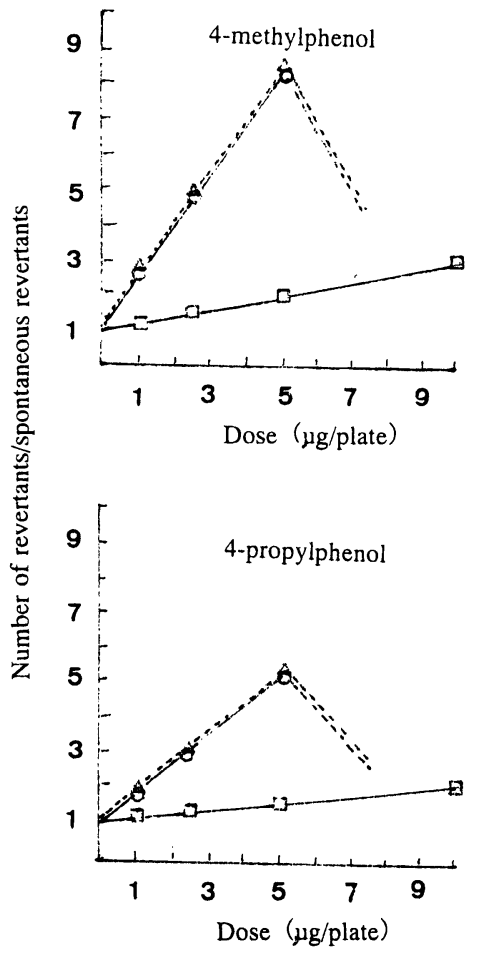

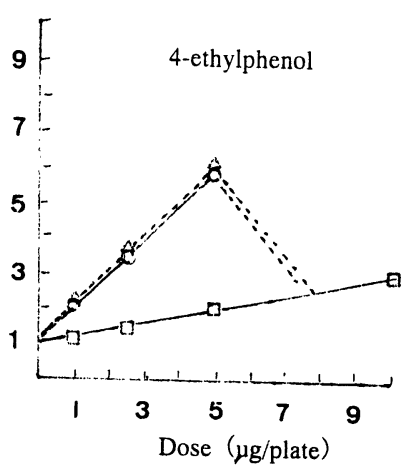

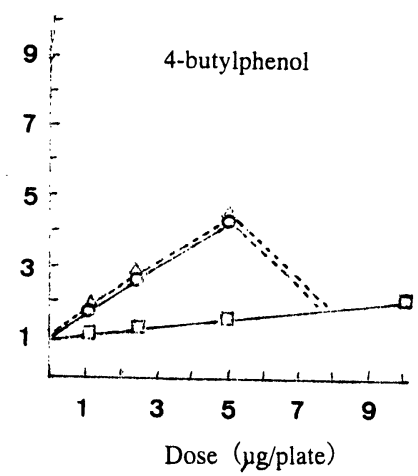

Fig. 3 Mutaginicity of the original extracts of chlorine-treated 4-alkylphenol solutions and polyamide TLC fractions 3 and 7 against $S$. typhimurium TA100 without S9 mix

Each point on the dose-response curves represents the average of triplicate determination - - original extracts; $\square=$ fraction $3 ;-\square-=$ fraction 7 

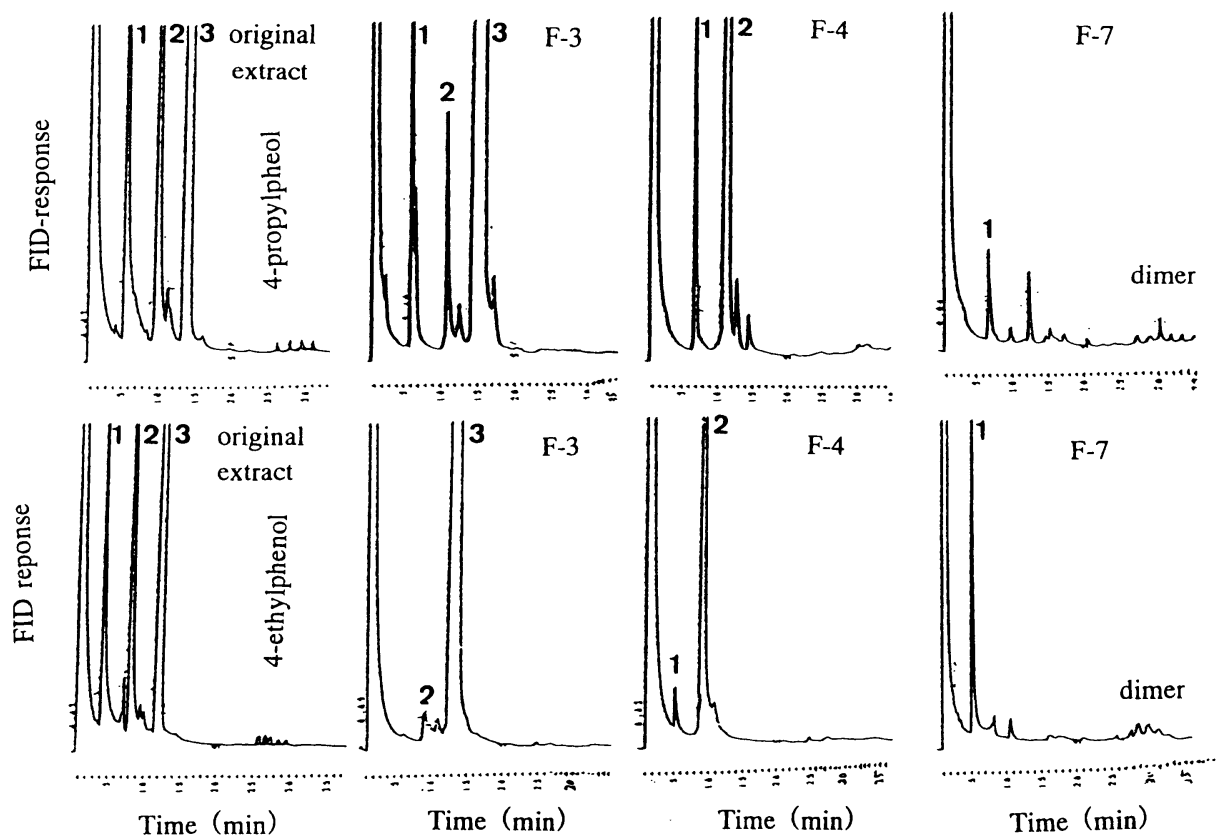

Fig. 4 Gas chromatograms (flame ionization detection) of the original extracts of 4 -alkylphenols and polyamide TLC fractions 3,4 and 7

For main compounds, see text; for GC conditions, see EXPERIMENTAL

uted mainly in fraction 4 , but these compounds exhibited no mutagencity response. Polychlorinated 4alkylphenol dimers were also distributed in fractions 6 and 7 , increasing amount and mutagencity. Fraction 7 , with a weak mutagencity response, consisted of a mixture of di-, tri- and tetrachlorinated 4-alkylphenol dimers. These compounds have been shown previously ${ }^{13,15,16)}$ to be the mutagenic materials in the extracts from the 4alkylphenol solutions after treatment with a high chlorine dose at $\mathrm{pH} 7$ for $1 \mathrm{~h}$.

Each fraction 3 in Fig. 2, with the highest mutagenic response (Fig. 3), consisted of unknown compounds corresponding to the peak 3 in Fig. 4, and their purity were over $90 \%$ by GC determinations with flame ionization detection. The gas chromatograms in Fig. 4 also show that these compounds are the major component in the original extracts. Therefore, it seems that these compounds, formed by the reactions of 4-alkylphenols with chlorine in an acidic aqueous solutions, contribute to the mutagenicity of the chlorinated 4-alkylphenol solutions.

Figure 5 shows the mass spectra of unknown compounds that correspond to each TLC fraction 3 in Fig. 2 and peak 3 in Fig. 4, with the highest mutagenic re- sponse, and their mass spectrometric interpretations are also presented in Table 2. The unknown compounds gave the molecular ions $\left(\mathrm{M}^{+}\right)$at $\mathrm{m} / \mathrm{z} 192$ for the 4-methyl-, 206 for the 4-ethyl-, 220 for the 4propyl- and 234 for the 4-butylphenol-hypochlorite reaction products, respectively, with two chlorine atoms. The most abundant fragment ions at $\mathrm{m} / \mathrm{z} 177\left(\mathrm{M}^{+}{ }^{+}\right.$ alkyl) and $\mathrm{m} / \mathrm{z} 157\left(\mathrm{M}^{+}-\mathrm{Cl}\right.$ for the methyl-), $171\left(\mathrm{M}^{+}\right.$$\mathrm{Cl}$ for the ethyl-), $185\left(\mathrm{M}^{+}-\mathrm{Cl}\right.$ for the propyl-) and 199 $\left(\mathrm{M}^{+}-\mathrm{Cl}\right.$ for the butylphenol reaction product), respectively, were also observed in each mass spectrum in Fig. 5. These findings indicate the occurrence of $\mathrm{C}_{7} \mathrm{H}_{5} \mathrm{Cl}_{2} \mathrm{O}_{2}, \mathrm{C}_{8} \mathrm{H}_{7} \mathrm{Cl}_{2} \mathrm{O}_{2}, \mathrm{C}_{9} \mathrm{H}_{9} \mathrm{Cl}_{2} \mathrm{O}_{2}$ and $\mathrm{C}_{10} \mathrm{H}_{11} \mathrm{Cl}_{2} \mathrm{O}_{2}$ in the highest mutagenic fraction 3 . On the basis of these MS interpretations for TLC fraction 3 and that obtained previously ${ }^{9)}$, the mutagenic compounds present in the fraction 3 may be 2,6-dichloro-4-hydroxy-4alkylcyclohexa-2, 5-dien-1-ones.

\section{CONCLUSIONS}

The compounds responsible for the mutagenic response could be completely isolated from the diethyl ether-extractable products of the reactions of 4-alkylphenols with hypochlorous acid in acidic aqueous solu- 

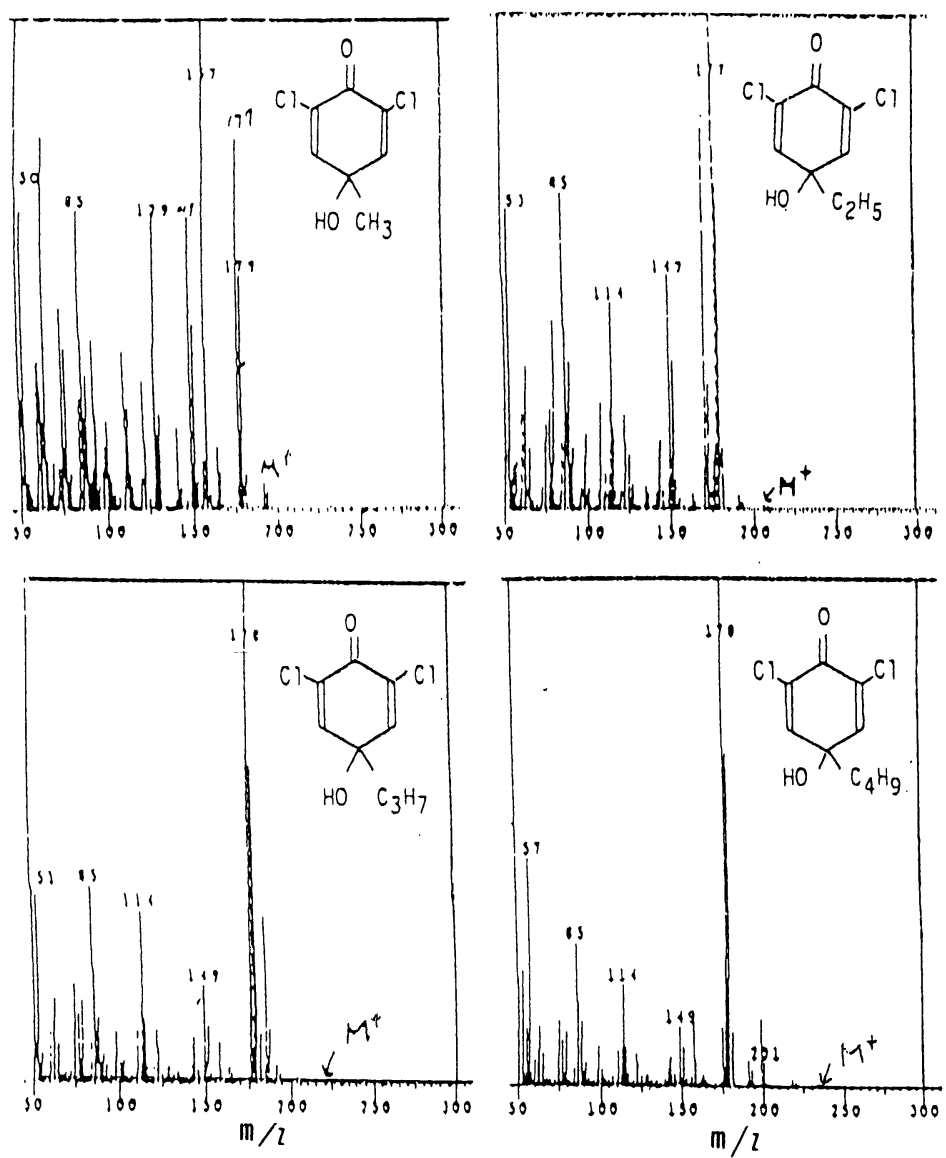

Fig. 5 Mass spectra (EI-MS) of the unknown compounds corresponding to the peak 3 in the chromatogram in Fig. 4 and to the fraction 3 in the thin-layer chromatogram in Fig. 2

Table 2 Mass spectrometric (EI-MS) characterization of 2,6-dichloro-4-hydroxy-4-alkylcyclohexa-2,5-dien-1ones (chloroalkylsemiquinones) occurring in the mutagenic diethyl ether extracts from chloirnetreated 4 -alkylphenol solutions ( $\mathrm{pH}$ 5)

\begin{tabular}{|c|c|}
\hline Compound tested & $\begin{array}{l}\text { EI-MS fragmentation (EI, } 70 \mathrm{eV}) \\
\mathrm{m} / \mathrm{z} \text { [fragment ion, relative intensity }(\%)]\end{array}$ \\
\hline 1. Chloromethylsemiquinone & $\begin{array}{l}192\left(\mathrm{M}^{+}, 5\right), 177\left(\mathrm{M}^{+}-\mathrm{CH}_{3}, 70\right), 157\left(\mathrm{M}^{+}-\mathrm{Cl}, 100\right), 149\left(\mathrm{M}^{+}-\right. \\
\left.\mathrm{CH}_{3}-\mathrm{CO}, 44\right), 129\left(\mathrm{M}^{+}-\mathrm{Cl}-\mathrm{CO}, 55\right), 111\left(\mathrm{M}^{+}-?, 30\right), 85\left(\mathrm{M}^{+}-\right. \\
\left.\mathrm{CH}_{3}-\mathrm{Cl}-\mathrm{CO}-\mathrm{COH}, 56\right)\end{array}$ \\
\hline 2. Chloroethylsemiquinone & $\begin{array}{l}206\left(\mathrm{M}^{+}, 0.8\right), 177\left(\mathrm{M}^{+}-\mathrm{C}_{2} \mathrm{H}_{5}, 100\right), 171\left(\mathrm{M}^{+}-\mathrm{Cl}, 72\right), 149\left(\mathrm{M}^{+}\right. \\
\left.-\mathrm{C}_{2} \mathrm{H}_{5}-\mathrm{CO}, 44\right), 114\left(\mathrm{M}^{+}-\mathrm{C}_{2} \mathrm{H}_{5}-\mathrm{Cl}-\mathrm{CO}, 39\right), 85\left(\mathrm{M}^{+}-\mathrm{C}_{2} \mathrm{H}_{5}-\mathrm{Cl}-\mathrm{CO}-\right. \\
\mathrm{COH}, 60)\end{array}$ \\
\hline 3. Chloropropylsemiquinone & $\begin{array}{l}220\left(\mathbf{M}^{+}, 0.8\right), 185\left(\mathbf{M}^{+}-\mathrm{Cl}, 30\right), 178\left(\mathbf{M}^{+}-\mathrm{C}_{3} \mathrm{H}_{6}, 100\right), 149\left(\mathbf{M}^{+}\right. \\
\left.-\mathrm{C}_{3} \mathrm{H}_{7}-\mathrm{CO}, 27\right), 114\left(\mathbf{M}^{+}-\mathrm{C}_{3} \mathrm{H}-\mathrm{Cl}-\mathrm{CO}, 31\right), 85\left(\mathrm{M}+-\mathrm{C}_{3} \mathrm{H}_{7}-\mathrm{Cl}-\mathrm{COH}\right. \\
, 36)\end{array}$ \\
\hline 4. Chlorobuthylsemiquinone & $\begin{array}{l}234\left(\mathrm{M}^{+}, 0.5\right), 199\left(\mathrm{M}^{+}-\mathrm{Cl}, 11\right), 178\left(\mathbf{M}^{+}-\mathrm{C}_{4} \mathrm{H}_{8}, 100\right), 163\left(\mathbf{M}^{+}\right. \\
-?, 12), 149\left(\mathbf{M}^{+}-\mathrm{C}_{4} \mathrm{H}_{9}-\mathrm{CO}, 10\right), 114\left(\mathbf{M}^{+}-\mathrm{C}_{4} \mathrm{H}_{9}-\mathrm{Cl}-\mathrm{CO}, 11\right), 85 \\
\left(\mathbf{M}^{+}-\mathrm{C}_{4} \mathrm{H}_{9}-\mathrm{Cl}-\mathrm{CO}-\mathrm{COH}, 22\right)\end{array}$ \\
\hline
\end{tabular}


tions. The compounds isolated was mutagenic in the TA100 strain without mammalian metabolic activation, and their mutagenic potentials were ranged from 2.5 for the 4-nonylphenol- to 24 revertants per nmol for the 4-methylphenol-hypochlorite reaction product. GC/MS studies of the mutagenic components isolated suggested that these compounds are probably 2,6dichloro-4-hydroxy-4-alkylcyclohexa-2,5-dien-1ones (chlorinated semiquinones) which have yet to be identified. Therefore, subsequent investigations will be conducted to identify and determine the chlorinated semiquinones in chlorine-treated waters, such as pulp mill effluents, industrial wastewater and drinking water.

\section{REFERENCES}

1) Pelon, W., Whitman, B.F. and Beasly, T.W.: Reversion of histidine-dependent mutant strains of Salmonella typhimurium by Mississippi River water samples. Environ. Sci. Technol., 11, 619-623 (1977)

2) Loper, J.C.: Mutagenic effects of organic compounds in drinking water. Mutation Res., 76, 241268 (1980)

3) Glatz, B.A., Criswell, C.D., Aguello, N.D., Svec, H.T., Fritz, J.S., Grimm, S.M. and Thomson, M.A.: Examination of drinking water for mutagenic activity. J. Am. Water Works Assoc., 70, 465-468 (1978)

4) Maruoka, S. and Yamanaka, S.: Production of mutagenic substances by chlorination of waters. Mutation Res., 79, 381-386 (1980)

5) Cheh, A.M., Skochpole, J., Koski, P. and Cole, L.: Non-volatile mutagens in drinking water: Production by chlorination and destruction by sulfite. Science, 207, 90-92 (1980)

6) Holmbon, B.R., Voss, R.H., Mortimer, R.D. and Wong, A.: Fractionation, isolation and characterization of Ames mutagenic compounds in kraft chlorination effluents. Environ. Sci. Technol., 18, 333337 (1984)

7) Kronberg, L. and Vartiainen, V.: Ames mutagenicity and concentration of the strong mutagen, 3-chloro4-(dichloromethyl)-5-hydroxy-2(H)-furanone and its geometric isomer E-2-chloro-3-dichloro-methyl-4oxo-butenoic acid in chlorine-treated tap waters. Mutation Res., 206, 177-182 (1988)
8) Rapson, W.H., Nazar, M.A. and Sutsky, V.: Mutagenicity produced by a aqueous chlorination of organic compounds. Bull. Environ. Contam. Toxicol., 24, 590596 (1980)

9) Onodera, S., Uchida, A. and Nakajima C.: Thinlayer chromatographic fractionation of Ames mutagenic chlorosemiquinone in chlorinated 4-methylphenol solution. J. Chromatogr. A, 699, 291-296 (1995)

10) Onodera, S., Yoshimatsu, K. and Yonaha, M.: Transformation of aqueous phenolic compounds in the presence of natural organics and chlorine into Ames mutagenic chloro-o-benzoquinones. J. Environ. Chem., 7, 31-37 (1997)

11) Onodera, S., Yoshimatsu, K., Saitoh, H. and Uchida, A.: Behavior of mutagenic formation from phenolic compounds in water disinfection with chlorine and their mutagenic potential formation. Jpn J. Toxicol. Environ. Health, 44, 289-299(1998)

12) Ahel, M. and Gieger, W.: Determination of alkylphenols and alkylphenol mono- and diethoxylates in environment samples by high-performance liquid chromatography. Anal. Chem., 57, 1577-1583 (1985)

13) Onodera, S., Yamashita, M., Ishikura, S. and Suzuki, S.: Thin-layer chromatographic fractionation of Ames mutagenic compounds in chlorinetreated 4-methylphenol solution. J. Chromatogr, 360, 137-150 (1986)

14) Onodera, S., Yoshimatsu, K., Nakano, S., Saitoh, H. and Suzuki, S.: The mutagenic and some physico-chemical properties of organic residues obtained from drinking water by Amberlite XAD-2 and activated carbon extraction. Eisei Kagaku, 34, 389-400 (1988)

15) Onodera, S., Takahashi, M. and Suzuki, S.: Production of alkylpolychlorinated phenoxyphenols (predioxins) by aqueous chlorination of alkylphenols. Jpn J. Toxicol. Environ. Health, 39, 20-28 (1993)

16) Onodera, S., Takahashi, M., Ogawa, M. and Suzuki, S.: Mutagenicity of polychlorophenoxy- phenols (predioxins) and their photo-degradation products in aqueous solution. Jpn J. Toxicol. Environ. Health, 41, 212-219 (1995) 